Original paper

\title{
Radiological protection for pregnant women at a large academic medical Cancer Center
}

\author{
Bae Chu ${ }^{\text {a,* }}$, Daniel Miodownik ${ }^{a}$, Matthew J. Williamson ${ }^{a}$, Yiming Gao a , Jean St. Germain ${ }^{\text {a }}$, \\ Lawrence T. Dauer ${ }^{\mathrm{a}, \mathrm{b}}$
}

a Department of Medical Physics, Memorial Sloan Kettering Cancer Center, 1275 York Ave, NY, NY, USA

${ }^{\mathrm{b}}$ Department of Radiology, Memorial Sloan Kettering Cancer Center, 1275 York Ave, NY, NY, USA

\section{A R T I C L E I N F O}

\section{Article history:}

Received 2 March 2017

Received in Revised form 7 April 2017

Accepted 9 April 2017

Available online 27 April 2017

\section{Keywords:}

Occupational safety

Pregnancy

Fetus

Radiation protection

\begin{abstract}
A B S T R A C T
Purpose: Most radiation protection programs, regulations and guidance apply specific restrictions to the occupational exposure of pregnant workers. The aim of this study was to compile data from the declared pregnant woman (DPW) radiation protection program over more than 5 years at a large, high-volume, comprehensive oncology academic/medical institution and to evaluate for effectiveness against existing regulations and guidance.

Methods: A retrospective review was performed of the data collected as part of the DPW radiation protection program from January 2010 through May 2016, including the number of declared pregnancies, worker category, personal and fetal dosimetry monitoring measurements, workplace modifications, as well as the monthly and total recorded badge results during the entire pregnancy.

Results: 245 pregnancies were declared. The mean monthly fetal radiation dosimetry result was $0.009 \mathrm{mSv}$ with a median of $0.005 \mathrm{mSv}$ and a maximum of $0.39 \mathrm{mSv}$. The mean total dose over the entire pregnancy was estimated to be $0.08 \mathrm{mSv}$ with a median of $0.05 \mathrm{mSv}$ and a maximum of $0.89 \mathrm{mSv}$. Only 8 (3.2\%) of the 245 declared pregnancies required that workplace modifications be implemented for the worker.

Conclusions: The implementation of a declared pregnancy and fetal assessment program, careful planning, an understanding of the risks, and minimization of radiation dose by employing appropriate radiation safety measures as needed, can allow medical staff to perform procedures and normal activities without incurring significant risks to the conceptus, or significant interruptions of job activities for most medical workers.
\end{abstract}

() 2017 Associazione Italiana di Fisica Medica. Published by Elsevier Ltd. This is an open access article under the CC BY-NC-ND license (http://creativecommons.org/licenses/by-nc-nd/4.0/).

\section{Introduction}

Individuals who work in occupations that use radioactive materials or radiation sources can be exposed as a result of proximity to such sources or materials [1]. Many medical staff work in an occupation with the potential for radiation exposure, including staff involved in fluoroscopically guided procedures, radiologic technologists, nuclear medicine technologists, radiochemists who prepare or use radiopharmaceuticals, brachytherapy physicists or physicians, nurses, and others [2,3]. These exposures occur in many modalities ranging from handling small amounts of radioactive

\footnotetext{
* Corresponding author at: Department of Medical Physics, Memorial Sloan Kettering Cancer Center, 1275 York Ave., New York, NY 10021, USA.

E-mail addresses: chub@mskcc.org(B.Chu), miodownd@mskcc.org(D. Miodownik), willim01@mskcc.org(M.J.Williamson),gaoy1@mskcc.org(Y.Gao), stgermaj@mskcc.org (J. St. Germain), dauerl@mskcc.org (L.T. Dauer).
}

material for diagnostic studies to administration (and care) of therapeutic quantities of radioactive materials to the operation of radiation-producing equipment. The use of radiation in the medical field is growing, and the number of exposed workers is on the rise [3].

The National Council on Radiation Protection and Measurements (NCRP) estimated that the mean annual effective dose during 2006 was $0.75 \mathrm{mSv}$ for medical workers in the United States [4] and recordable doses for medical workers during 2002 was $1.6 \mathrm{mSv}$ and for interventional radiology/cardiology was $3.0 \mathrm{mSv}$ worldwide [2]. For example, at our high-volume hospital, the mean annual effective dose during 2011 for physicians involved in fluoroscopically guided interventions was $1.6 \mathrm{mSv}$, and for technicians and nurses involved in such interventions was $1.1 \mathrm{mSv}$ [3]. For most radiation workers, exposure to low-level ionizing radiation is an accepted part of the job, however, pregnant radiation workers may have heightened concerns about the risks to their unborn 
child [6-8]. NCRP Report No. 174 [1] recently comprehensively reviewed the health effects and protective guidance on preconception and prenatal radiation doses.

Guidelines to minimize risk to the patient and conceptus have been developed for patients, including pregnant women, who may need medical radiography [9-11]. In addition, several guidelines have been developed for occupational radiation protection of pregnant women [1,5,12-16].

Most radiation protection programs, regulations and guidance apply specific restrictions to the occupational exposure of pregnant workers. For example the ICRP recommends that the embryo and fetus be protected to the same level as provided for members of the general public [17]. For occupational workers, the ICRP and the European Commission recommend that, after a worker has declared her pregnancy, her working conditions should ensure that the equivalent dose to the unborn child is maintained as low as is reasonably achievable (ALARA) and unlikely to exceed $1 \mathrm{mSv}$ during at the least the remainder of the pregnancy [17,18]. This is specifically mandated in the International Basic Safety Standards [19].

In the United States, Nuclear Regulatory Commission (NRC) requires that if worker activities are such that an individual could receive more than $1 \mathrm{mSv}$ (annual effective dose), the occupational radiation protection program is required to have a fetal assessment program [20]. Such a program typically includes training, historical dose assessments, counselling, monitoring, worker practice modifications when appropriate, and ongoing monthly and end-of declaration of pregnancy review. The NRC identifies a declared pregnant woman (DPW) as an occupational radiation worker who has voluntarily informed her employer, in writing, of her pregnancy and the estimated date of conception. The NRC also requires facilities to ensure that the dose equivalent to the embryo/fetus during the entire pregnancy, due to the occupational exposure of a declared pregnant woman, does not exceed $5 \mathrm{mSv}$ [21]. If the dose equivalent to the embryo/fetus is found to have exceeded $5 \mathrm{mSv}$, or is within $0.5 \mathrm{mSv}$ of this dose, by the time the woman declares the pregnancy, facilities are deemed to be in compliance if the additional dose equivalent to the embryo/fetus does not exceed $0.5 \mathrm{mSv}$ during the remainder of the pregnancy [21]. In addition, facilities shall make efforts to avoid substantial variation above a uniform monthly exposure rate to a DPW [21]. To that end, the NCRP recommends a monthly equivalent dose limit of $0.5 \mathrm{mSv}$ to the embryo/fetus (excluding medical and natural background radiation) once the pregnancy is known in order to control exposure during potentially sensitive periods of gestation [22]. The NCRP does not currently believe that specific controls are required for occupationally exposed women who are not know to be pregnant [22].

The purpose of this retrospective study was to compile data and evaluate for effectiveness the DPW radiation protection program from January 2010 through May 2016 for Memorial Sloan Kettering Cancer Center (MSKCC), a large, high-volume, comprehensive oncology academic and medical institution.

\section{Methods}

A fetal monitoring dosimetry badge (optically stimulated luminescence type badge) (Luxel ${ }^{\circledR}$, Landauer, Glenwood, Illinois) is provided to all DPW. The fetal monitoring badge is worn around the waist/midsection of the DPW (and under lead aprons when they are utilized). These badges are assigned for 10 months or until written notification of the end of the declaration is received.

A retrospective institutional review board approved review was performed of the data collected as part of the DPW radiation protection program from January 2010 through May 2016, including the number of declared pregnancies, personal and fetal dosimetry monitoring measurements, workplace modifications, worker category, as well as the monthly and total recorded badge results during the entire pregnancy. The minimum recordable dose for radiation monitors by the vendor is $0.01 \mathrm{mSv}$. Any value lower (between $0.000 \mathrm{mSv}$ and $0.009 \mathrm{mSv}$ ) is reported as "M" for minimal. All badge data reported as $<0.01 \mathrm{mSv}$ were set to $0.005 \mathrm{mSv}$ as a conservative approach. Dose received during the pregnancy prior to declaration was estimated based on prior monthly dosimetry results and were included when estimating total dose during the entire pregnancy. Mean, median, and maximum dose values were determined for individual monthly badge results, and the total estimated during the entire pregnancy.

\section{Results}

Approximately 5000 employees are issued radiation dosimetry monitoring badges at MSKCC. The employees represent all types of worker categories typical for an academic/medical hospital/ research center with specialties that focus on radiology, oncology surgery, radiation therapy, and chemotherapy. In total nearly 60,000 badges are distributed yearly. These badges include whole body, extremity, lens of eye, and fetal monitors.

Between January 2010 and May 2016, 245 pregnancies were declared. A DPW was provided and wore fetal radiation dosimetry badges each month between 1 and 10 months during their gestational period, depending on how far along they were in their pregnancy at the time of declaration. The average DPW received 6 unique monthly monitors during their declaration. In total, 1556 monthly fetal radiation dosimetry monitors were issued, measured and reviewed.

Of the 1556 monthly fetal radiation dosimetry monitors issued, 1403 (90.3\%) did not have measurable results $\geq 0.01 \mathrm{mSv}$ and 153 (9.8\%) fetal dosimetry monitors recorded measureable results $\geq 0.01 \mathrm{mSv}$. The 153 fetal dosimetry monitors with recorded measureable results $\geq 0.01 \mathrm{mSv}$ were worn during 74 unique declared pregnancies. The mean dose to the fetus during the whole pregnancy for the 74 pregnancies was $0.15 \mathrm{mSv}$ with a median of $0.075 \mathrm{mSv}$. The maximum dose to a fetus was $0.89 \mathrm{mSv}$. Job categories that received measureable results $\geq 0.01 \mathrm{mSv}$ included: radiology nursing, nuclear pharmacists, nuclear medicine technologists, interventional radiology technologists, pediatric outpatient clinic nurses, radiology technologists, endoscopy nurses/physicians, and Department of Medicine physicians. Radiology nursing represented the most frequent category in which a DPW monthly fetal radiation dosimetry monitor had results greater than $\geq 0.01 \mathrm{mSv}$ (Fig. 1 ).

The mean of all of the 1556 monthly fetal radiation dosimetry results was $0.009 \mathrm{mSv}$ with a median of $0.005 \mathrm{mSv}$ and a maximum of $0.39 \mathrm{mSv}$. Of the 245 declared pregnancies, the mean total dose over the entire pregnancy was estimated to be $0.08 \mathrm{mSv}$ with a median of $0.05 \mathrm{mSv}$ and a maximum of $0.89 \mathrm{mSv}$. No restrictions or work modifications were required for most of the declared pregnancies. Only 8 (3.2\%) of the 245 declared pregnancies required that workplace modifications be implemented for the worker during the declaration period.

\section{Discussion}

This study has shown that for 245 declared pregnancies at a large, high-volume, comprehensive oncology academic and medical institution, the maximum reported monthly dose was $0.39 \mathrm{mSv}$, which is below the NCRP guidance of $0.5 \mathrm{mSv}$ in a month [22], and the maximum reported total dose over a pregnancy was $0.89 \mathrm{mSv}$, which is below both the NRC limit of $5 \mathrm{mSv}[21]$ and the 


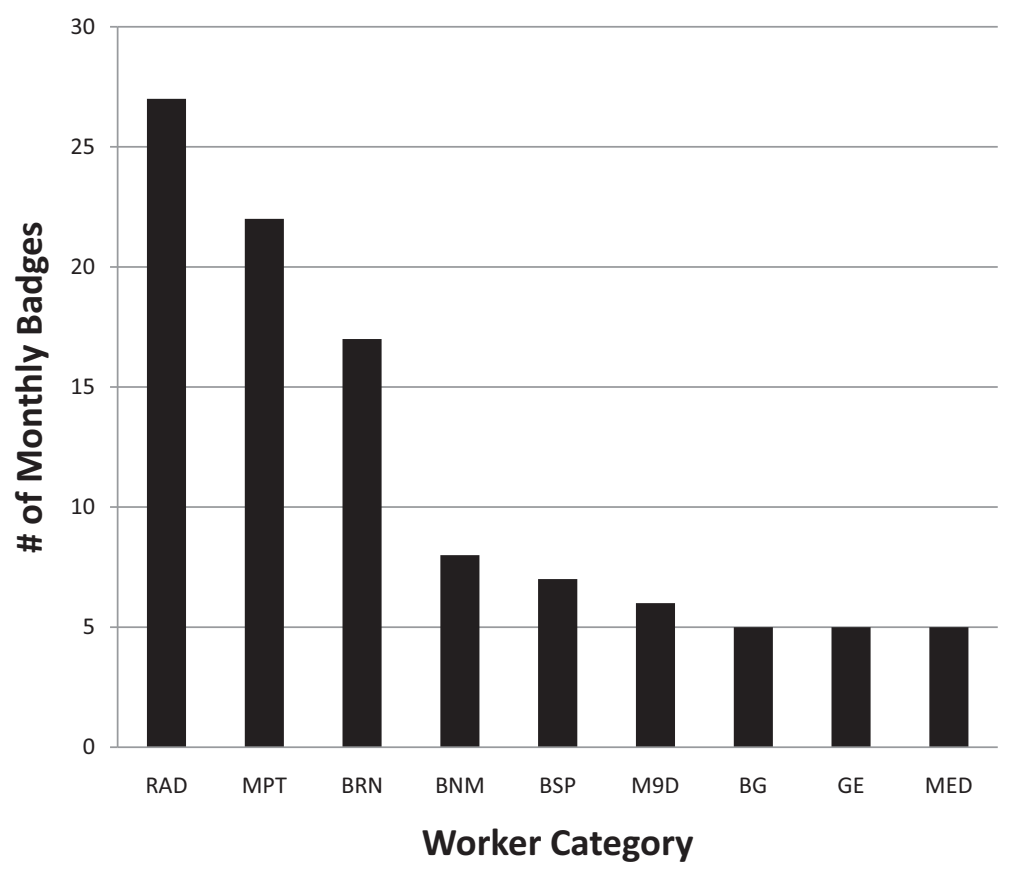

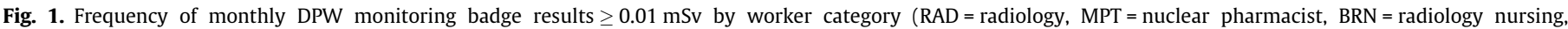

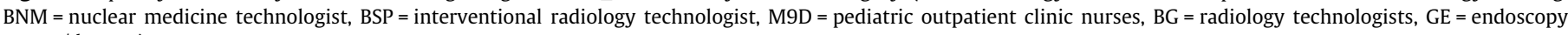
nurses/doctors)

ICRP limit of $1 \mathrm{mSv}$ [17]. In our study, the median (25th percentile, 75 th percentile) total pregnancy dose was $0.05(0.05,0.055) \mathrm{mSv}$. Sensakovic et al. [23] collected badge data from 180 pregnancies for a large multisite hospital system and reported a median (25th percentile, 75th percentile) total pregnancy dose of 0.009 (0.006, $0.06) \mathrm{mSv}$.

MSKCC trains (initially and annually) all employees that may be exposed to radioactive material or radiation. This training includes specifics on the hospital administrative policy and procedure for employees to voluntarily declare their pregnancy. Upon declaration, a revised occupational dose limit is instituted in accordance with NRC regulations [21,24]. In order for the reduced dose limit to apply, the employee voluntary declares her pregnancy in writing with the estimated date of conception $[1,21]$. Every effort is implemented to ensure uniform doses of less than $0.5 \mathrm{mSv}$ per month are maintained. The employee has the ability to speak to a health physicist to review previous work history and doses and to confidentially discuss questions or concerns about working with radiation during the declaration period. A copy of NRC, Regulatory Guide 8.13, Instructions Concerning Prenatal Radiation Exposure [24] is provided to all individuals being counselled by the health physicist about the declared pregnancy program.

Our institution does not make workplace modifications requested by pregnant workers unless it is deemed necessary based on the NRC limits and NCRP guidance. Historical personal dose data can provide a useful estimate of the potential for doses during declared pregnancies [5] and can be used in the evaluation through the individual's own dosimetry record data or among the data from colleagues with similar work descriptions. During a declared pregnancy, we specifically evaluate each fetal monitor on a monthly basis. Although rare, in the case of an unexpected exposure, we would send the fetal dosimeter out for an emergency reading, estimate a fetal dose and determine how much radiation exposure the employee could receive for the remainder of the pregnancy, with work modifications as necessary.

When historical dosimetry data reveals that the pregnant worker has normally been receiving less than $0.1 \mathrm{mSv}$ per month, workplace evaluation may not be necessary. If the pregnant worker is typically receiving more than $0.1 \mathrm{mSv}$ per month, or is expected to receive more than $1 \mathrm{mSv}$ in the 10 month gestational period, the need for workplace modifications are evaluated. In such cases, the sources of ionizing radiation are identified and best practices determined to reduce radiation exposure, such as the minimizing time spent with higher activity sources or radionuclide patients, performing low-dose rate manual brachytherapy procedures, increasing the distance from the source of radiation and shielding as appropriate [1]. In the event that workplace modifications are necessary, the DPW is informed that their supervisors may need to be contacted in order to implement appropriate measures to maintain radiation dose limits and guidelines for the embryo/fetus. The monthly dose reports for DPW are reviewed monthly and maintained by the Health Physics department. In the event that the report indicates radiation readings that have the potential to fall outside of the dose guidelines, the employee is contacted and additional work adjustments are evaluated/implemented where appropriate.

Although most DPW did not require workplace modifications, necessary modifications were able to be implemented where appropriate. Modifications were specific to the exposure situation for the DPW and may have included minimal changes, providing an electronic dosimeter, shielding when necessary, maximizing the time spent with patients before radionuclide treatment and minimizing the time spent with patients after administration, or increasing distance to radionuclide patients. More significant modifications may have included transferring the employee to a different area with similar job functions to decrease radiation dose, decreasing the number of radionuclide patient interactions, decreasing the number of injections of radionuclides given by the pregnant worker, and discontinuing radioiodine labelling and/or dispensing of radioiodine by a DPW. Although additional counselling was rarely needed after the initial discussions with DPW, the information from the NCRP, ICRP, and professional societies was helpful during such counselling situations $[1,5,12-16]$. 
Occupationally exposed radiation workers who have declared their pregnancy should be monitored monthly and provided with their monthly dose record [1]. A limitation is that the fetal monitoring dosimeter typically overestimates the actual dose to the conceptus because radiation attenuation by the mother's tissues is not considered $[25,26]$. Some have suggested that the dose to the embryo and fetus can generally be approximated as one half of the personal equivalent dose at $1 \mathrm{~cm}$, for dosimeters worn at the abdomen/waist $[27,28]$. ICRP Publication 84 further indicates that fetal doses likely do not exceed $25 \%$ of the personal dosimeter measurement [12]. This value depends on the penetration of the radiation (i.e., on the energy). Therefore, in this study, a more accurate mean embryo/fetus dose over the entire course of the reviewed pregnancies can be estimated to be in the range of about 0.02-0.04 mSv.

\section{Conclusions}

This review has shown that an active declared pregnancy and fetal assessment program can ensure that doses are maintained below monthly guidelines and well below regulatory limits over the course of the pregnancy. The implementation of a declared pregnancy and fetal assessment program, careful planning, an understanding of the risks, and minimization of radiation dose by employing appropriate radiation safety measures as needed, can allow medical staff to perform procedures and normal activities without incurring significant risks to the conceptus, or significant interruptions of job activities for most medical workers.

\section{Acknowledgements}

The authors thank James Keller, Department of Medical Physics, MSKCC, for assistance in developing this manuscript. This work was partially supported by the National Institutes of Health/ National Cancer Institute Cancer Center Support Grant P30 CA008748.

\section{References}

[1] NCRP. Preconception and Prenatal Radiation Exposure: Health Effects and Protective Guidance. NCRP Report. Bethesda, MD: National Council on Radiation Protection and Measurements; 2013.

[2] UNSCEAR. Effects of Ionizing Radiation. Report to the General Assembly, with Annexes, vol. 1. New York: United Nations; 2008.

[3] Dauer LT. Exposed medical staff: challenges, available tools, and opportunities for improvement. Health Phys 2014;106:217-24.

[4] NCRP. Ionizing Radiation Exposure of the Population of the United States. Bethesda, MD: NCRP Publications; 2009.

[5] Dauer LT, Miller DL, Schueler B, Silberzweig J, Balter S, Bartal G, et al Occupational radiation protection of pregnant or potentially pregnant workers in IR: a joint guideline of the Society of Interventional Radiology and the Cardiovascular and Interventional Radiological Society of Europe. J Vasc Interv Radiol 2015;26:171-81.

[6] Nickoloff EL, Brateman L, Hendee M, William R. Proposition: a pregnant resident physician should be excused from training rotations such as angiography and nuclear medicine because of the potential exposure of the fetus. Med Phys 1999;26:2517-9.

[7] Brent RL. Counseling patients exposed to ionizing radiation during pregnancy. Rev Panamer Salud Públ 2006;20:198-204.

[8] Shaw PM, Vouyouka A, Reed A. Time for radiation safety program guidelines for pregnant trainees and vascular surgeons. J Vasc Surg 2012;55(862-8):e2.

[9] ACR. ACR-SPR Practice Parameter for Imaging Pregnant or Potentially Pregnant Adolescents and Women with Ionizing Radiation. ACR Practice Parameters, Technical Standards and Appropriateness Criteria. American College of Radiology; 2013.

[10] Stecker MS, Balter S, Towbin RB, Miller DL, Vañó E, Bartal G, et al. Guidelines for patient radiation dose management. J Vasc Interv Radiol 2009;20:S263-73.

[11] Dauer LT, Miller DL, Damilakis J, Dixon RG, Marx MV, Schueler BA, et al. Radiation management for interventions using fluoroscopic or computed tomographic guidance during pregnancy: a joint guideline of the Society of Interventional Radiology and the Cardiovascular and Interventional Radiological Society of Europe with Endorsement by the Canadian Interventional Radiology Association. J Vasc Interv Radiol 2012;23:19-32.

[12] ICRP. Pregnancy and medical radiation: ICRP Publication 84. Annals of the ICRP. 2000;30:1-39.

[13] IAEA. Applying Radiation Safety Standards in Nuclear Medicine. Vienna: International Atomic Energy Agency; 2005.

[14] IAEA. Applying Radiation Safety Standards in Radiotherapy. Vienna: International Atomic Energy Agency; 2006.

[15] Cruz-Suarez R, Nosske D, Souza-Santos D. Radiation protection for pregnant workers and their offspring: a recommended approach for monitoring. Radiat Prot Dosimetry 2011;144:80-4

[16] Santos J, Nunes R. Ethical issues related to professional exposure of pregnant women in the medical field: monitoring and limiting effective dose. Radiat Prot Dosimetry 2011;144:525-9.

[17] ICRP. The 2007 Recommendations of the International Commission on Radiological Protection. ICRP Publication 103. Annals of the ICRP. 2007;37:1-332.

[18] Council of the European Union. Council Directive 2013/59/Euratom of 5 December 2013 laying down basic safety standards for protection against the dangers arising from exposure to ionising radiation, and repealing Directives 89/618/Euratom, 90/641/Euratom, 96/29/Euratom, 97/43/Euratom and 2003/ 122/Euratom. Off J Eur Union 2013;L13:1-73.

[19] IAEA. Radiation Protection and Safety of Radiation Sources: International Basic Safety Standards. Vienna: International Atomic Energy Agency; 2011.

[20] Best PJ, Skelding KA, Mehran R, Chieffo A, Kunadian V, Madan M, et al. SCAI consensus document on occupational radiation exposure to the pregnant cardiologist and technical personnel. Catheterization Cardiovasc Intervent 2011:77:232-41.

[21] NRC. Dose equivalent to an embryo/fetus. In: Commission USNR, editor. 10 CFR Part 201208. Washington, DC: U.S. Nuclear Regulatory Commission; 1998.

[22] NCRP. Limitation of Exposure to Ionizing Radiation. NCRP Report. Bethesda, MD: National Council on Radiation Protection and Measurements; 1993.

[23] Sensakovic WF, Flores M, Hough M. Occupational dose and dose limits: experience in a large multisite hospital system. J Am College Radiol 2016;13:649-55.

[24] NRC. Instruction Concerning Prenatal Radiation Exposure. In: Commission USNR, editor. Regulatory Guide 813. Washington, DC: U.S. Nuclear Regulatory Commission; 1999.

[25] NCRP. Radiation Dose Management for Fluoroscopically-Guided Interventional Medical Procedures. NCRP Report. Bethesda, MD: National Council on Radiation Protection and Measurements; 2010.

[26] Miller DL, Vañó E, Bartal G, Balter S, Dixon R, Padovani R, et al. Occupational radiation protection in interventional radiology: a joint guideline of the cardiovascular and interventional radiology society of europe and the society of interventional radiology. Cardiovasc Inter Rad 2010;33:230-9.

[27] Trout ED. Isodose curves in a phantom due to diagnostic quality X-radiation. Health Phys 1977;33:359-67.

[28] Faulkner K, Marshall N. Personal monitoring of pregnant staff in diagnostic radiology. J Radiol Prot 1993;13:259-66. 